\title{
Serotyping and subtyping of Neisseria meningitidis isolates by co-agglutination, dot-blotting and ELISA
}

\author{
E. WEDEGE, E. A. HØIBY*, E. ROSENOVIST and L. O. FRØHOLM
}

Departments of Methodology and "Bacteriology, National Institute of Public Health, Geitmyrsveien 75, 0462 Oslo 4, Norway

\begin{abstract}
Summary. Typing of meningococci with a panel of serotype and subtype specific monoclonal antibodies (MAbs) was compared in co-agglutination, dot-blotting and ELISA tests. Twenty reference strains, 50 case isolates and 133 throat isolates from healthy carriers were studied. The typing results with dot-blotting and ELISA were identical, whereas co-agglutination gave different results for three case and 24 carrier strains. The distribution of serotypes and subtypes among the strains is reported. The combination of the subtypes P1.1 and P1.15 in a serotype 15 patient strain was observed. With one case strain and 15 carrier strains, neither serotype nor subtype could be determined. Non-typable and non-subtypable isolates were further characterised by sodium dodecyl sulphate-polyacrylamide gel electrophoresis. Coagglutination is useful for typing small numbers of strains with a few MAbs, but less suitable for large-scale typing than the other two methods. Dot-blotting needs less expensive equipment, smaller volumes of antibodies and fewer manipulations than ELISA.
\end{abstract}

\section{Introduction}

Neisseria meningitidis is one of the main causes of bacterial meningitis throughout the world. Meningococci are classified into serogroups based on the immunological specificity of the capsular polysaccharides ${ }^{1-3}$ and further subdivided into serotypes and subtypes as reviewed by Frasch et $a l .{ }^{4}$ The serotype specificity resides on the outer membrane porin proteins, being either a class 2 or 3 protein; the subtype specificity is based on antigenic differences in the class 1 outer membrane protein.

Serotyping of meningococci has become important in the characterisation of patient and carrier strains. Monoclonal antibodies (MAbs) have provided more specific methods than those relying on polyclonal sera. ${ }^{5}$ Several techniques in which MAbs are used for serotyping have been reported, e.g., coagglutination, ${ }^{6}$ dot-blotting, ${ }^{7}$ filter radio-immunoassay, ${ }^{8}$ whole-cell ELISA ${ }^{9}$ and latex agglutination. ${ }^{10}$ The aim of this investigation was to compare three of these methods, co-agglutination, dotblotting and ELISA, for serotyping and subtyping of case and carrier isolates with a panel of MAbs and to ascertain the preferred method for routine analyses. The strains studied were the reference strains described by Frasch et $a l^{4}$ and recent

Received 2 May 1989; accepted 14 Sep. 1989. isolates from cases and carriers in Norway. Nontypable and non-subtypable isolates were also analysed by sodium dodecyl sulphate-polyacrylamide gel electrophoresis (SDS-PAGE).

\section{Materials and methods}

\section{Meningococcal strains}

The 20 reference strains ${ }^{4}$ were provided by $\mathrm{Dr} \mathrm{C}$. E. Frasch, Center for Biologics Evaluation and Research, Bethesda, MD, USA, Dr J. T. Poolman, National Institute of Public Health and Environmental Hygiene, Bilthoven, The Netherlands and Dr W. D. Zollinger, Department of Bacterial Diseases, Walter Reed Army Institute of Research, Washington DC, USA.

Fifty consecutive isolates from patients with meningococcal disease in the period autumn 1987 to spring 1988, including the reference strain 44/76 (15: P1.16), were obtained from Dr E. Holten, Akershus Central Hospital, Nordbyhagen, Norway. During the same period, 133 strains were isolated from the throats of 56 army recruits participating in a meningococcal vaccine trial. Up to four isolates were obtained from the same individual in a 12-week period. These strains were provided by Dr G. Bjune and Dr J. Eng, National Institute of Public Health, Oslo, Norway. Throat swabs were transported in modified Stuart's medium ${ }^{11}$ and plated on selective medium ${ }^{12}$ the same day. Clones were obtained by subcultivation of single colonies twice and then stored in Greave's solution at $-70^{\circ} \mathrm{C}$. 


\section{Monoclonal antibodies}

MAbs with specificities against serotypes 2a (1-1-P2a), 2b (3-1-P2b), 2c (5-1-P2c), 4 (15-1-P4), 11 (9-1-P11), 15 (3-1-P15), 21 (14-1-P21) and subtypes P1.1 (9-1-P1.1), P1.2(3-1-P1.2), P1.3(12-1-P1.3), P1.15(2-1-P1.15), P1.16 (3-1-P1.16) and against a common epitope on class 1 proteins (9-1-P1C) were supplied by $\mathrm{Dr} \mathrm{W}$. D. Zollinger. MAbs against serotypes 1 (MN3 C6B), 5 (MN2 B3H), 6 (MN1 B4C), 9 (MN5 C10D), 14 (MN5 C8C) and subtype P1.9 (MN5 A10F) were received from Dr J. T. Poolman. The MAb against serotype $8(2725 \mathrm{H} 6)$ was obtained from Dr C. E. Frasch and that against P1. Ham from Dr F. E. Ashton, Bureau of Microbiology, Laboratory Center for Disease Control, Ottawa, Canada.

\section{Co-agglutination test}

Co-agglutination was performed by a modification of the method described by Frøholm et al. ${ }^{6}$ Bacteria, grown overnight on Kellogg's agar plates, were harvested in $5 \mathrm{ml}$ of phosphate-buffered saline (PBS) and inactivated in a boiling water bath for $20 \mathrm{~min}$. After centrifugation, the pellet was washed once in merthiolate $0.01 \%$ in PBS, resuspended in $2 \mathrm{ml}$ of the same solution and stored at $4^{\circ} \mathrm{C}$. The co-agglutination reagent was made by mixing $1 \mathrm{ml}$ of Pansorbin (Calbiochem Corporation, La Jolla, $\mathrm{CA}$, USA) with $0.1 \mathrm{ml}$ of the MAb, and the test was performed as previously described. ${ }^{6}$

\section{ELISA}

The whole-cell ELISA procedure of Abdillahi and Poolman ${ }^{9}$ was used with minor modifications. Strains were grown overnight on Kellogg's agar plates. Cells were suspended in PBS with sodium azide $0.02 \%$ and heat inactivated at $56^{\circ} \mathrm{C}$ for $30 \mathrm{~min}$. The absorbance of the suspensions was adjusted to an optical density of about 0.1 at $650 \mathrm{~nm}\left(c .1 \times 10^{8} \mathrm{cfu} / \mathrm{ml}\right)$ and stored at $4^{\circ} \mathrm{C}$. Antigen-coated microtitration plates, prepared by evaporation of the whole-cell suspensions $(100 \mu \mathrm{l} /$ well $)$ overnight at $33^{\circ} \mathrm{C}$, were washed with Tween $800.05 \%$ in distilled water and incubated with MAbs for $1 \mathrm{~h}$ at $33^{\circ} \mathrm{C}$. Antibody binding was detected after incubation at $33^{\circ} \mathrm{C}$ for 90 min with alkaline phosphatase-linked anti-mouse Ig (1 in 1000) (Sigma Chemicals). The substrate was pnitrophenyl phosphate $(1 \mathrm{mg} / \mathrm{ml})$ in $0.5 \mathrm{M}$ diethanolamine buffer, $\mathrm{pH} 9 \cdot 8$. Absorbance was read at $405 \mathrm{~nm}$ after $25-$ $45 \mathrm{~min}$ in a Dynatech Microplate Reader. Optimal concentrations of antigens and MAbs were determined by chessboard titrations. The dilutions of MAbs used in ELISA ranged from 1 in 500 to 1 in 32000 .

\section{Dot-blotting}

Dot-blots were incubated with the primary and secondary antibodies as previously described..$^{13}$ Briefly, whole-cell suspensions $(2 \mu \mathrm{l})$, as used in the ELISA, were dotted $1 \mathrm{~cm}$ apart on nitrocellulose (Bio-Rad Laboratories; $0.45-\mu \mathrm{m}$ pore size) strips $(0.5 \times 10 \mathrm{~cm})$. After drying for $30 \mathrm{~min}$ at room temperature, strips were transferred to Accutran 8-well incubation trays (Schleicher \& Schuell $\mathrm{GmbH}$, Dassel, West Germany) and blocked for $30 \mathrm{~min}$ in bovine serum albumin 3\% in PBS. Up to five strips, dotted with 49 test strains plus one reference strain, could be incubated in one well with $2 \mathrm{ml}$ of blocking buffer, care being taken that the strips were thoroughly wetted with buffer. MAbs were pipetted directly into the blocking buffer, at dilutions ranging from 1 in 10000 to 1 in 60000 , except for anti-P1.Ham which was diluted 1 in 2000 . After overnight incubation, strips were washed separately in their wells four times with PBS, collected in one box for two final washings, and then incubated for $2 \mathrm{~h}$ with rabbit anti-mouse Ig conjugated to peroxidase (1 in 2000) (Dakopatts a/s, Denmark). Strips were photographed with a green filter and stored in plastic covers.

Dot-blotting was performed with all the MAbs listed above, but MAbs 9-1-P1C and anti-P1.Ham were not used in ELISA. Co-agglutination was performed with MAbs against serotypes $2 \mathrm{a}, 2 \mathrm{~b}, 4,15$ and subtypes $\mathrm{P} 1.2$, $\mathrm{P} 1.3, \mathrm{P} 1.15$ and P1.16. Serotyping and subtyping results by the three methods were analysed blindly.

\section{SDS-PAGE and immunoblotting}

SDS-PAGE was performed in polyacrylamide $12 \%$ mini-gels $(7 \times 8 \mathrm{~cm}$; thickness $0.75 \mathrm{~mm})$ as described by Laemmli. ${ }^{14}$ Whole-cell suspensions $(70 \mu \mathrm{l})$, as used in dot-blotting and ELISA, were boiled for $5 \mathrm{~min}$ with sample buffer $(40 \mu \mathrm{l})$ containing 2 -mercaptoethanol ${ }^{14}$ and $15-\mu \mathrm{l}$ samples were transferred into wells formed by a 15-tooth comb (Bio-Rad Laboratories). The gels were stained with Coomassie Brilliant Blue. Outer membrane preparations from $N$. meningitidis strains M986 (2a: P1.2) and 44/76 (15: P1.16) served as markers for the class 1,2 and 3 proteins of decreasing molecular weights. ${ }^{4}$ Immunoblotting was performed as previously described. ${ }^{13,15}$

\section{Results}

\section{Meningococcal reference strains}

Reaction patterns of the MAbs with the reference strains were studied by all methods. The serotype and subtype results were expressed according to the identification system described by Frasch et al., ${ }^{4}$ in which each strain is characterised by a serotype number followed by the class 1 protein (P1) subtype (table I). Dot-blots of nine reference strains with 13 MAbs are shown in fig. 1. The dot-blotting and ELISA methods gave reproducible results, and positive strains were clearly distinguished from negative strains. Except for the distinct serotype-4 reaction of the serotype-21 reference strain (ATCC 13077) in ELISA, which was negligible on dot-blots (table I and fig. 1), identical results were obtained with the two methods. Only weak cross-reactions 
Table 1. Serotypes and subtypes of meningococcal reference strains by dot-blotting and ELISA

\begin{tabular}{|c|c|c|c|}
\hline \multirow{2}{*}{$\begin{array}{l}\text { Reference } \\
\text { serotype }\end{array}$} & \multirow{2}{*}{$\begin{array}{l}\text { Reference } \\
\text { strain }\end{array}$} & \multicolumn{2}{|c|}{ Serotype and subtype results by } \\
\hline & & Dot-blotting & ELISA \\
\hline 1 & M1080 & 1:P1.1* & 1: P1.1 \\
\hline $2 a$ & B16B6 & 2a:P1.2 & 2a:P1.2 \\
\hline $2 \mathrm{~b}$ & 2996 & $2 \mathrm{~b}: \mathrm{P} 1.2$ & $2 \mathrm{~b}: \mathrm{Pl} .2$ \\
\hline $2 c$ & 2396 & $2 c: P 1.2$ & $2 \mathrm{c}: \mathrm{Pl} .2$ \\
\hline 3 & $126 \mathrm{E}$ & 8:P1.2 & $8: P 1.2$ \\
\hline 4 & M981 & 4: -†‡ & 4:- \\
\hline 5 & M992 & 5: P1.1* & 5:P1.1 \\
\hline 6 & M990 & $6(1):-$ & $6(1):-$ \\
\hline 8 & M978 & 8: P1.1* & 8:P1.1 \\
\hline 9 & M982 & 9:P1.9 & 9:P1.9 \\
\hline 11 & M136 & $11(1):-\dagger \ddagger$ & 11:- \\
\hline 12 & S-3032 & NT: P1.16 & NT: P1.16 \\
\hline 14 & S-3446 & $14:-$ & $14:-$ \\
\hline 15 & $\mathrm{H} 355$ & 15:P1.15† & 15: P1.15 \\
\hline 16 & $60 \mathrm{E}$ & NT:P1.1* & NT: P1.1 \\
\hline 17 & 6557 & NT: - & NT: - \\
\hline 18 & $190 I$ & $8:-$ & $8:-$ \\
\hline 19 & 6940 & 8:- & 8:- \\
\hline 20 & $35 \mathrm{E}$ & $2 c: P 1.1$ & 2c:P1.1 \\
\hline 21 & ATCC 13077 & $21:-\dagger \ddagger$ & $21 / 4:-$ \\
\hline
\end{tabular}

NT, not-typable; -, non-subtypable.

* Reacts with anti-P1.Ham.

$\dagger$ No reaction with MAb 9-1-P1C.

$\ddagger$ Class 1 protein not detected in SDS-gels. were observed. In both procedures, the serotype- 6 reference strain (M990) showed a weak serotype-1 reaction and the serotype-9 MAb a moderate binding to its reference strain with a noticeable background (table I and fig. 1). The serotype-6 $\mathrm{MAb}$ also produced similar background staining in ELISA, whereas on dot-blots the serotype-11 strain (M136) cross-reacted weakly with the serotype-1 MAb. Low dilutions of the subtype-specific MAbs caused some cross-reactions on dot-blots. These reactions became negligible or disappeared when higher dilutions ( 1 in 30000 to 1 in 40000 ) were used and when care was taken not to transfer the MAb solutions between the wells during the first washing step.

Four of the prototype strains carried the serotype8 epitope (126E, M978, $190 \mathrm{I}$ and 6940) and two the serotype-2c epitope (2396 and 35E). The MAb raised against subtype P1.Ham reacted on dot-blots with four of the five strains of subtype P1.1.

Three reference strains, M981 (4: -), M136 (11: $-)$, and ATCC $13077(21:-)$, did not show a class 1 protein in SDS-PAGE gels or bind with the MAb raised against a common class 1 protein determinant (9-1-P1C). In addition, the serotype-15 strain (H355) did not react with this MAb, although it did bind the subtype P1.15-specific MAb (2-1-P1.15).

Co-agglutination tests with the reference strains, which were performed only with MAbs against

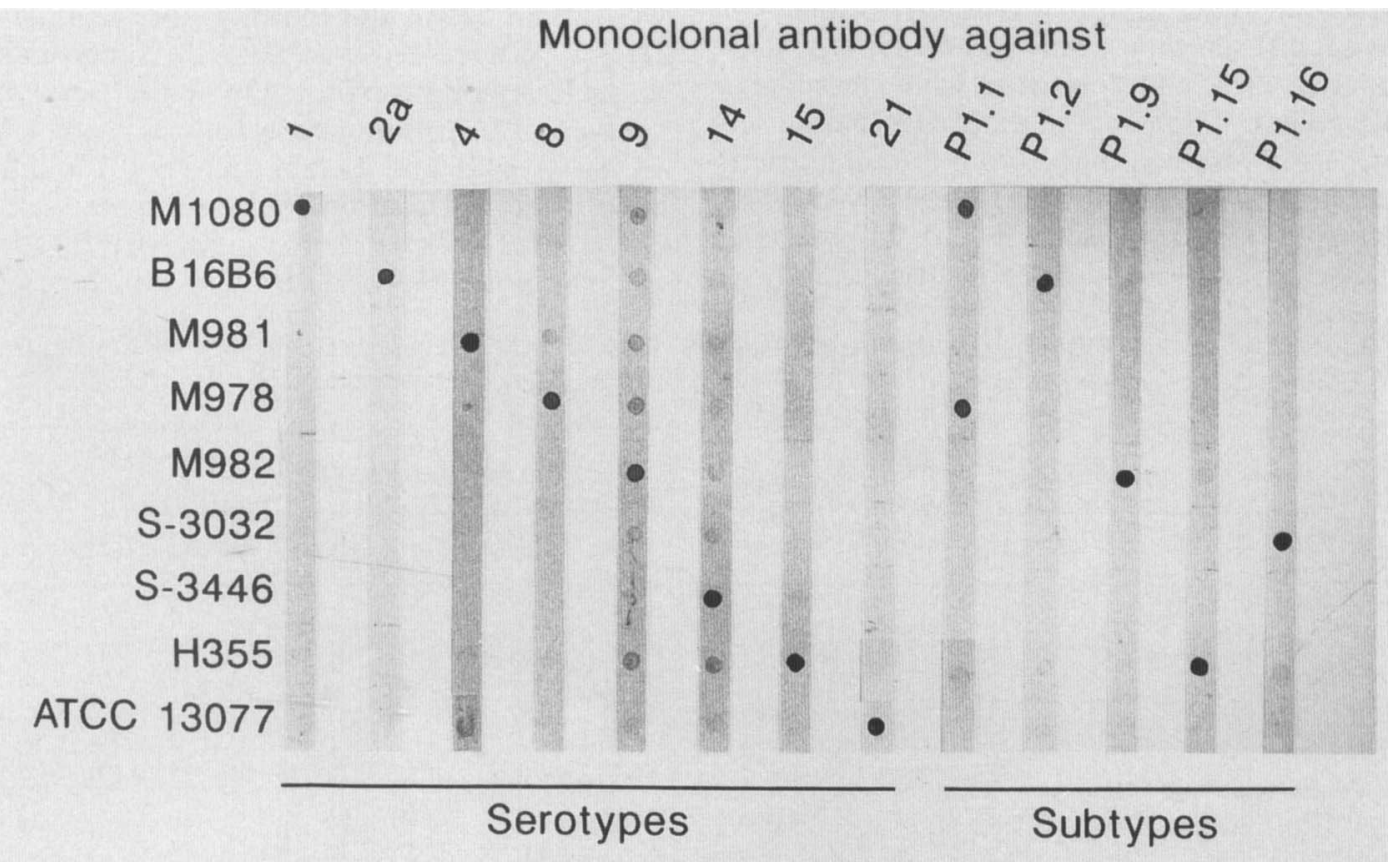

Fig. 1. Dot-blots of whole-cell suspensions of nine meningococcal reference strains incubated with various serotype-specific and subtype-specific MAbs. 
serotypes $2 \mathrm{a}, 2 \mathrm{~b}, 4,15$ and subtypes P1.2, P1.3, $\mathrm{P} 1.15$ and P1.16 (see Materials and methods), showed specific reactions of these MAbs with their corresponding prototype strains.

Generally, co-agglutination could only be performed with boiled antigens; $5 \mathrm{~min}$ and $60 \mathrm{~min}$ treatments gave identical reactions. The dotblotting and ELISA methods worked equally well with antigens heated to $56^{\circ} \mathrm{C}$ for $30 \mathrm{~min}$ or with boiled antigens. The typing results with these two methods did not change after storage of the wholecell suspensions for 1 year at $4^{\circ} \mathrm{C}$. Both procedures permitted typing of single bacterial colonies. They could also be performed in a shorter time by reducing the drying time of the cell suspensions in ELISA or the incubation time and the dilutions of MAbs in dot-blotting.

\section{Case isolates}

Identical results for the serotypes and subtypes of the strains from patients with meningococcal disease were found with dot-blotting and ELISA (table II). Serotypes 15 and $2 \mathrm{a}$ were the most frequent, constituting $70 \%$ and $16 \%$ of the strains, respectively; $8 \%$ were non-typable. Serotypes 4,8 and 21 were represented by one strain each. The most prevalent subtype was P1.16 (56\%) followed by about the same proportions $(20 \%)$ of $\mathrm{P} 1.2$ and non-subtypable strains.

Because co-agglutination was not performed with MAbs against serotypes 8 and 21 and subtype P1.1, strains with these characteristics were classified as non-typable or non-subtypable. Otherwise, coagglutination results differed from the other methods only in that two single strains, 8: P1.1 and NT: P1.16 (table II), reacted weakly with MAbs raised against serotypes 15 and 4, respectively, and one

Table II. Serotypes and subtypes by dot-blotting and ELISA of meningococcal case strains

\begin{tabular}{|c|c|c|c|c|c|c|c|c|}
\hline \multirow{2}{*}{$\begin{array}{l}\text { Sub- } \\
\text { types }\end{array}$} & \multicolumn{6}{|c|}{ Serotypes } & \multirow[b]{2}{*}{ Total } & \multirow{2}{*}{$\begin{array}{c}\text { Percentage } \\
\text { of total } \\
\text { strains }\end{array}$} \\
\hline & $2 a$ & 4 & 8 & 15 & 21 & NT & & \\
\hline P1.1 & $\ldots$ & $\ldots$ & 1 & $\ldots$ & $\ldots$ & 1 & 2 & 4 \\
\hline P1.2 & 6 & $\ldots$ & $\ldots$ & 1 & 1 & 1 & 9 & 18 \\
\hline P1.15 & $\ldots$ & $\ldots$ & $\ldots$ & $1^{*}$ & $\ldots$ & $\ldots$ & 1 & 2 \\
\hline P1.16 & $\ldots$ & $\ldots$ & $\ldots$ & 27 & $\ldots$ & 1 & 28 & 56 \\
\hline NST & 2 & 1 & $\ldots$ & 6 & $\ldots$ & 1 & 10 & 20 \\
\hline Total & 8 & 1 & 1 & 35 & 1 & 4 & 50 & \\
\hline & 16 & 2 & 2 & 70 & 2 & 8 & $\ldots$ & 100 \\
\hline
\end{tabular}

* This 15: P1.15 strain (185/87) also had subtype P1.1. NT, non-typable; NST, non-subtypable. non-subtypable isolate showed a weak reaction with the MAb against P1.2.

One serotype-15 isolate $(185 / 87)$ reacted with both subtype-P1.1 and -P1.15 MAbs in dot-blotting and ELISA (table II). The same result was observed after selection and spreading of 10 single colonies of the strain to exclude a possible mixture of strains. Co-agglutination showed a weak reaction with the P1.15 MAb. SDS-PAGE and immunoblots of this strain and the reference strains with subtypes-P1.1 and $-\mathrm{P} 1.15$ (M1080 and H355) indicated that these two subtype epitopes were probably present on the same class 1 protein. The molecular weight was similar to that of the subtype-P1.15 protein, which moved slightly ahead of the P1.1 subtype protein in gels (fig. 2).

All six of the non-subtypable serotype-15 strains reacted with the MAb against a common class 1 protein epitope (9-1-P1C) and showed a class 1 protein in SDS gels. However, three of the other four non-subtypable case strains did not bind $\mathrm{MAb}$ 9-1-P1C and only one of these showed a class 1 protein in gels. Class 2 proteins were demonstrated in two of the four non-typable strains by SDSPAGE and the lower molecular weight class 3 proteins in the other two strains.

\section{Carrier isolates}

The serotypes and subtypes of the carrier strains were identical in dot-blotting and ELISA (table III); $71 \%$ were serotypable, $61 \%$ subtypable and only $11 \%$ could be assigned to neither serotype nor subtype. The commonest serotypes were $4(22 \%)$, $14(16 \%), 8,15$ and $21(8 \%$ each $)$ and 1 and $2 a(5 \%$ each). The distribution of the subtypes was P1.15 $(19 \%), \mathrm{P} 1.2(16 \%), \mathrm{P} 1.3(13 \%), \mathrm{P} 1.16(8 \%)$ and P1.1 $(5 \%)$. Subtype P1.9 and serotypes 2 b, 2c, 5, 6, 9 and

Table III. Serotypes and subtypes by dot-blotting and ELISA of meningococcal carrier strains

\begin{tabular}{|c|c|c|c|c|c|c|c|c|c|c|}
\hline \multirow{2}{*}{$\begin{array}{l}\text { Sub- } \\
\text { types }\end{array}$} & \multicolumn{8}{|c|}{ Serotypes } & \multirow[b]{2}{*}{ Total } & \multirow{2}{*}{$\begin{array}{c}\text { Percentage } \\
\text { of total } \\
\text { strains }\end{array}$} \\
\hline & 1 & $2 a$ & 4 & 8 & 14 & 15 & 21 & NT & & \\
\hline P1.1 & $\cdots$ & $\cdots$ & $\cdots$ & $\cdots$ & $\ldots$ & ... & 3 & 4 & 7 & 5 \\
\hline P1.2 & .. & 5 & $\ldots$ & 4 & 6 & $\ldots$ & $\ldots$ & 6 & 21 & 16 \\
\hline P1.3 & $\ldots$ & $\ldots$ & 1 & $\ldots$ & 2 & $\ldots$ & 6 & 9 & 18 & 13 \\
\hline P1.15 & 3 & $\ldots$ & 14 & 5 & $\ldots$ & ... & $\ldots$ & 3 & 25 & 19 \\
\hline P1.16 & $\ldots$ & $\ldots$ & 5 & $\ldots$ & ... & 3 & $\ldots$ & 2 & 10 & 8 \\
\hline NST & 4 & 2 & 10 & 1 & 13 & 7 & $\ldots$ & 15 & 52 & 39 \\
\hline Total & 7 & 7 & 30 & 10 & 21 & 10 & 9 & 39 & 133 & $\ldots$ \\
\hline$\%$ & 5 & 5 & 22 & 8 & 16 & 8 & 7 & 29 & $\cdots$ & 100 \\
\hline
\end{tabular}

NT, non-typable; NST, non-subtypable. 
11 were not represented. On dot-blots, a weak crossreaction of the P1.2 subtype MAb with all 15 : and 15: P1.16 strains was seen. The former strains showed a class 1 protein in SDS gels.

Excluding differences related to the restricted number of MAbs used, co-agglutination gave different results for $24(18 \%)$ of the 133 strains compared with dot-blotting and ELISA. The major difference was that 10 strains, shown to be serotype 8 in dot-blotting and ELISA, were classified as either serotype 4 or non-typable by co-agglutination. Four further strains had distinct serotypes by co-agglutination, and 10 strains had different subtypes, among them five strains with subtype P1.3 that were non-subtypable by co-agglutination.

Thirty six $(27 \%)$ isolates, comprising all 25 strains of subtype P1.15, eight NT:- strains, one 1:and two 2a:- strains (table III), did not bind the class 1 protein MAb 9-1-P1C. SDS-PAGE showed no class 1 protein in seven of these 11 nonsubtypable strains, including six of the NT:strains. The majority of the NT: - carrier strains, with or without reaction with MAb 9-1-P1C, demonstrated a class 2 protein pattern in gels.

\section{Discussion}

Three methods for typing meningococci-coagglutination, dot-blotting and ELISA - were compared in tests with a panel of MAbs specific for different serotypes and subtypes. Reference, case and carrier strains were studied. The serogroups and multilocus enzyme genotypes of the case and carrier strains will be reported separately. The specificities of the serotype and subtype MAbs were investigated by testing the reference strains by all methods. Classification of the reference strains into serotypes and subtypes was identical with the three techniques except for one strain. Dot-blotting and ELISA gave the same typing results for the case and carrier strains, but co-agglutination showed different results for $6 \%$ of the case isolates and $18 \%$ of the carrier strains. The main differences were that all serotype 8 carrier strains were judged to be either serotype 4 or non-typable in co-agglutination, and that nearly a third of the P1.3 subtype carrier strains were non-subtypable by co-agglutination. Co-agglutination deviated less from the two other methods in typing of the systemic strains. Concordant typing results of patient strains by ELISA and co-agglutination were observed by Käyhty et al. ${ }^{16}$

All the methods were reproducible, but the distinction between positive and negative results with test strains was clearer in dot-blotting and ELISA. These two techniques also produce a permanent record of the results, either as stained dots or absorbance values; the latter may be more convenient. Co-agglutination is suitable for typing meningococci with a small panel of MAbs, but is less convenient for large-scale screening when many

\section{Gels}

\section{Blots}

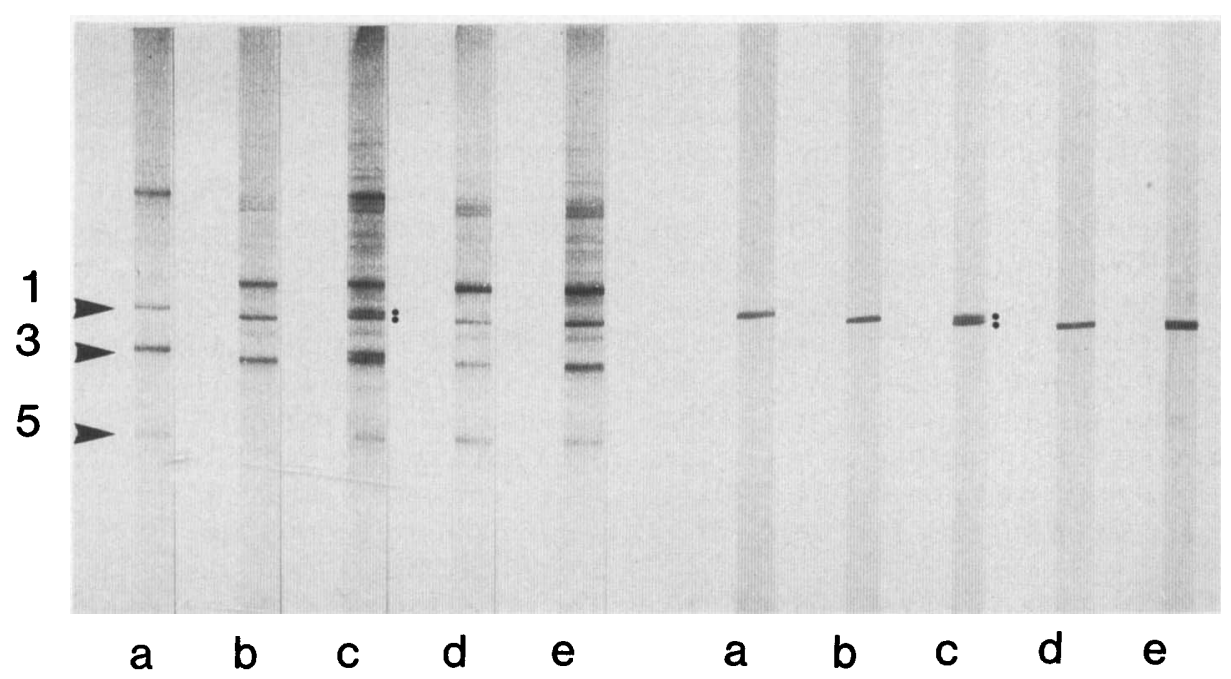

Fig. 2. SDS-gels and corresponding immunoblots of the reference strains M1080 (1:P1.1) and H355 (15:P1.15) and the case strain 185/87 (15: P1.1 + P1.15). The lanes contained the following strains: $\mathbf{a}, \mathrm{M} 1080 ; \mathbf{b}, \mathrm{H} 355 ; \mathbf{c}, \mathrm{M} 1080$ and $\mathrm{H} 355 ; \mathbf{d}, 185 / 87 ;$ and e, 185/ 87 and H355. The nitrocellulose strips were incubated with MAbs (1 in 5000) against subtype P1.1 (lane a), subtype P1.15 (lane b) or both subtypes reagents (lanes $\mathrm{c}-\mathrm{e}$ ). The dots in lane $\mathrm{c}$ indicate the two closely moving subclass proteins $\mathrm{P} 1.1$ and $\mathrm{P} 1.15$, the latter of slightly lower molecular weight. The positions of the class 1, 3 and 5 proteins are shown to the left. 
MAbs are employed. It is more time-consuming and requires larger volumes of MAb reagents than dot-blotting or ELISA. The ability of the antibody to bind to protein $\mathrm{A}$ is essential for this technique. Compared with ELISA, dot-blotting demands less expensive equipment, involves fewer manipulations and uses smaller volumes of MAbs. The time needed for analysis was about the same for these two methods.

The results of typing the prototype strains by dotblotting and ELISA corresponded with the results obtained by Abdillahi ${ }^{17}$ who used the whole-cell ELISA method ${ }^{9}$ with a similar, but not identical panel of MAbs. In both studies the serotype-1 MAb bound to both serotype- 6 and -11 reference strains. The reference strain for serotype 21 was recently found to be a serotype- 4 strain. ${ }^{18}$ In the present study it bound the serotype-4 and serotype-21 MAbs distinctly in ELISA, but only the serotype-21 MAb on dot-blots (table I and fig. 1). The serotype-21 $\mathrm{MAb}$, which was originally raised against a serogroup A strain from Brazil (W. D. Zollinger, personal communication), reacted with one systemic infection strain and nine carrier strains. The reaction with strains of subtype $\mathrm{P} 1.3$ was weaker than with those of subtypes P1.1 and P1.2. None of these strains bound the serotype-4 MAb.

In comparison with other recent carrier studies, in which co-agglutination was used for typing, ${ }^{19,20,21}$ a larger proportion of the carrier strains was typable. This is mainly explained by inclusion in the MAb panel of MAbs against serotypes 4, 8 and 14 , which together constituted $46 \%$ of the carrier serotypes. In contrast to the carrier studies, serotypes 1 and 14 and subtype P1.3 were not found among the case strains. Only $2 \%$ of the case isolates and $11 \%$ of the carrier isolates had neither serotype nor subtype. Serotypes 2b, 2c, 5, 6, 9 and 11 and subtype P1.9 were not found amongst either case or carrier isolates. However, the distribution of serotypes and subtypes is known to show geographical variations. The $\mathrm{P} 1.9$ subtype was demonstrated in $28 \%$ of Danish strains from systemic infections, but was absent or rare in strains isolated in 18 other countries. ${ }^{22}$ A survey of 215 case and carrier isolates by Poolman et al. ${ }^{23}$ showed no serotype- 9 strains and only two serotype- 6 and four serotype- 11 strains.

One case strain (185/87) reacted with MAbs against both serotypes $P 1.1$ and $P 1$.15. Experiments indicated that the two epitopes were present on the same class 1 protein (fig. 2). Norwegian systemic infection strains from 1969-1986 have previously been characterised by their serotype and multilocus enzyme genotype. ${ }^{24}$ In that study three isolates had the same genotype as strain 185/87 (D. A. Caugant, personal communication), and two of these also carried the combination of $\mathrm{P} 1.1$ and $\mathrm{P} 1.15$ subtypes shown by immunoblotting (unpublished results). These findings indicate an association of this particular class 1 protein subtype with a specific genotype. Various other combinations of subtypes were recently reported in meningococcal strains. ${ }^{25}$

The P1.Ham epitope has been identified on class 1 proteins of Canadian serotype-2b strains. ${ }^{26,27}$ The binding pattern of anti-Pl.Ham to the reference strains (table I) was similar to that of a MAb with specificity against subtype P1.7 (P1.1, 16) reported by Abdillahi and Poolman. ${ }^{22,25}$ These authors also found the P1.7 epitope on the $15: P 1.16$ prototype strain, strain $44 / 76 .^{22,25}$ In our laboratory, binding of anti-P1.Ham to strain $44 / 76$ and some $15: \mathrm{P} 1.16$ case strains has also been observed (data not shown).

Valuable information was obtained by SDSPAGE of the whole-cell meningococcal suspensions used as antigens in ELISA and dot-blotting. Compared with our and others ${ }^{4}$ experiences with gel electrophoretic patterns of outer membrane complexes, SDS-PAGE of whole-cell suspensions showed less class 5 proteins, a distinct band of molecular weight about 50000 above the class 1 proteins, and several weak higher molecular weight bands (fig. 2). The absence of class 1 proteins after gel electrophoresis of whole-cell suspensions of serotypes-4, -11 and -21 reference strains was in accordance with previous observations on isolated outer membrane vesicles, ${ }^{17,23,28}$ further indicating that purification of outer membrane vesicles was unnecessary for electrophoresis. SDS-PAGE analyses of the carrier strains without serotypes and subtypes showed that the majority had class 2 proteins. The cell suspensions were also suitable as antigens in immunoblotting (fig. 2).

The MAb 9-1-P1C, directed against a common epitope on class 1 proteins (P1C), did not bind to any of the P1.15 subtype case and carrier strains, indicating that the P1C epitope was probably not present on this subtype protein. The other 14 case and carrier isolates that did not react with anti-P1C were all non-subtypable, and the majority were also non-typable with the MAbs used. In SDS-PAGE only five of these strains showed a class 1 protein. Therefore, except for strains of subtype P1.15, the binding of anti-P1C to a meningococcal strain generally indicated the possesion of a class 1 protein. Five of the prototype strains M990, S-3446, $6557,190 \mathrm{I}$ and 6940 (table I) did not react with any subtype MAb, but bound anti-P1C and showed a class 1 protein in SDS-gels. The presence of a new 
subtype-P1.6 protein in four of these strains was recently reported by Abdillahi and Poolman. ${ }^{25}$

We are grateful to Drs F. E. Ashton, C. E. Frasch, J. T. Poolman and W. D. Zollinger for generously providing the

\section{REFERENCES}

1. Branham S E. Serological relationships among meningococci. Bacteriol Rev 1953; 17: 175-188.

2. Craven D E, Frasch C E, Robbins J B, Feldman H A. Serogroup identification of Neisseria meningitidis: comparison of an antiserum agar method with bacterial slide agglutination. J Clin Microbiol 1978; $7: 410-414$.

3. Gotschlich E C. The status of vaccines to meningococcal and gonococcal disease. Ann Inst Pasteur Microbiol $1985 ; 136 B$ : $341-355$.

4. Frasch C E, Zollinger W D, Poolman J T. Serotype antigens of Neisseria meningitidis and a proposed scheme for designation of serotypes. Rev Infect Dis 1985; 7: 504510 .

5. Sugasawara R J. The use of monoclonal antibodies for detecting and serotyping Neisseria meningitidis. In: Macario A J L, de Macario E C (eds) Monoclonal antibodies against bacteria. Vol II. Orlando, Academic Press. 1986: 61-79.

6. Frøholm L O, Bøvre K, Holten E, Zollinger W D. Serotyping of meningococci by coagglutination with monoclonal antibodies. NIPH Ann 1983; 6: 125-138.

7. Zollinger W D, Moran E E, Connelly H, Mandrell R E, Brandt B. Monoclonal antibodies to serotype 2 and serotype 15 outer membrane proteins of Neisseria meningitidis and their use in serotyping. Infect Immun $1984 ; 46$ : 260-266.

8. de Marie S, Hoeijemakers J H J, Poolman J T, Zanen H C. Filter radioimmunoassay, a method for large-scale serotyping of Neisseria meningitidis. J Clin Microbiol $1984 ; 20: 255-258$.

9. Abdillahi H, Poolman J T. Whole-cell ELISA for typing Neisseria meningitidis with monoclonal antibodies. FEMS Microbiol Lett 1987; 48: 367-371.

10. Bol P, Spanjaard L, Hopman C, Arends A, Kersten F, Zanen H C. Epidemiology of meningococcal (sub)types in the Netherlands. In: Poolman $\mathbf{J} T$ (ed) Gonococci and meningococci. Dordrecht, Kluwer Academic Publishers. 1988: 27-32.

11. Sandven P, Solberg O, Ødegaard K, Myhre G. Improved medium for the transportation of gonococcal specimens. Acta Pathol Microbiol Immunol Scand [B] 1982; 90: 73-77.

12. Ødegaard K, Solberg O, Lind J, Myhre G, Nyland B. Lincomycin in selective medium for the isolation of Neisseria gonorrhoeae. Acta Pathol Microbiol Scand [B] 1975; 83: 301-304.

13. Wedege E, Frøholm L O. Human antibody response to a group B serotype 2a meningococcal vaccine determined by immunoblotting. Infect Immun 1986; 51 : 571-578.

14. Laemmli $U K$. Cleavage of structural proteins during the assembly of the head of bacteriophage T4. Nature 1970; 227: 680-685.

15. Wedege E, Michaelsen T E. Human immunoglobulin G subclass immune responses to outer membrane antigens in meningococcal group B vaccine. J Clin Microbiol 1987 ; 25 : 1349-1353. prototype strains and the MAbs; to Dr E. Holten for supplying the case isolates and to Drs G. Bjune and J. Eng for the carrier strains. We thank D. A. Caugant and J. Eng for reviewing the manuscript and Ms K. Bolstad and B. Nyland for technical assistance.

16. Käyhty H, Sivonen A, Poolmann J, Peltola H, Eskola J, Mäkelä P H. Types and subtypes of group B meningococci isolated in Finland from 1976 through April 1986. In: Poolman J T (ed) Gonococci and meningococci. Dordrecht, Kluwer Academic Publishers. 1988 : 119124.

17. Abdillahi H. Monoclonal antibodies and Neisseria meningitidis. Typing and subtyping for epidemiological surveillance and vaccine development. Academic dissertation. Utrecht 1988: 160-163.

18. Abdillahi H, Crowe B A, Achtman M, Poolman J T. Two monoclonal antibodies specific for serotype 4 antigen of Neisseria meningitidis. Eur J Clin Microbiol Infect Dis 1988; 7: 293-296.

19. Caugant D A, Bøvre K, Gaustad P, Bryn K, Holten E, Høiby E A, Frøholm L O. Multilocus genotypes determined by enzyme electrophresis of Neisseria meningitidis isolated from patients with systemic disease and from healthy carriers. J Gen Microbiol $1986 ; 132$ : $641-652$.

20. Caugant D A, Kristiansen B E, Frøholm L O, Bøvre K, Selander R K. Clonal diversity of Neisseria meningitidis from a population of asymptomatic carriers. Infect Immun 1988; 56: 2060-2068.

21. Kristiansen B E, Lind K W, Mevold K et al. Meningococcal phenotypic and genotypic characteristics and human antibody levels. J Clin Microbiol 1988; 26: 1988-1992.

22. Abdillahi H, Poolman J T. Neisseria meningitidis group B serosubtyping using monoclonal antibodies in wholecell ELISA. Microb Pathog 1988; 4: 27-32.

23. Poolman J T, Hopman C T P, Zanen H C. Immunochemical characterization of Neisseria meningitidis serotype antigens by immunodiffusion and SDS-polyacrylamide gel electrophoresis immunoperoxidase techniques and the distribution of serotypes among cases and carriers. $J$ Gen Microbiol 1980; 116 : 465-473.

24. Frøholm L O, Holten E, Høiby E A, Caugant D A, Zollinger W D. Monitoring of systemic meningococcal isolates from Norway. In: Poolman J T (ed) Gonococci and meningococci. Dordrecht, Kluwer Academic Publishers. 1988: 105-108.

25. Abdillahi H, Poolman J T. Definition of meningococcal class 1 OMP subtyping antigens by monoclonal antibodies. FEMS Microbiol Immunol 1988; 47 : 139-144.

26. Brodeur B R, Larose $Y$, Tsang $P$, Hamel J, Ashton F, Ryan A. Protection against infection with Neisseria meningitidis group $B$ serotype $2 b$ by passive immunization with serotype-specific monoclonal antibody. Infect Immun 1985; 50: 510-516.

27. Ashton F E, Ryan J A, Diena B B, Zollinger W D. Monoclonal antibody analysis of meningococcal disease strains isolated in Canada. In: Poolman $\mathrm{J} \mathrm{T}$ (ed) Gonococci and meningococci. Dordrecht, Kluwer Academic Publishers. 1988: 15-19.

28. Tsai C M, Frasch C E, Mocca L F. Five structural classes of major outer membrane proteins in Neisseria meningitidis. J Bacteriol 1981 ; 146 : 69-78. 